\title{
Comentarios
}

\section{Debilidad y fortaleza de los diseños institucionales}

\section{Sobre las instituciones}

Aunque todavía hace falta mucho tiempo para que se lleven a cabo las elecciones de diputados a la Asamblea Legislativa y de Concejos Municipales la temática ya está presente en los medios de comunicación, bien sean éstos escritos, o bien sean audiovisuales. Estamos presenciando una especie de campaña adelantada. Esto en un doble sentido. Por un lado, las principales fuerzas electorales (ARENA y FMLN) han comenzado ya, de hecho, su campaña contra el adversario. Han comenzado a lanzarse acusaciones, a desprestigiarse mutuamente, a debilitar su imagen recíprocamente. Por otro lado, la disputa al interior de esos mismos partidos, seguida muy de cerca por diferentes medios de comunicación, ha servido para que los potenciales electores comienzen, si es que no lo han hecho ya, ha tomar su decisión: votar o abstenerse.

Pero, ¿es que acaso son tan importantes las elecciones de marzo del 2000 para soportar esta campaña adelantada? Cualquier analista de la política bien informado sabe que las elecciones de diputados y de concejos municipales son menos importantes que las elecciones presidenciales en regímenes presidencialistas como el salvadoreño. Lo mismo vale decir para las elecciones de diputados al Parlamento Centroamericano porque no hay que olvidar que también seremos convocados a votar para ello. Por tanto, ¿de dónde viene la importancia que los medios están dándole anticipa- damente a las elecciones del 2000? ¿Es un puro interés noticiero? ¿Es puro afán informativo? Propondré una respuesta a estas interrogantes más adelante. Primero deseo comentar algunos hechos que los mismos medios se han encargado de realzar o de sacar a luz pública.

Como lo señala el título de este trabajo quiero establecer una relación entre, por un lado, el diseño institucional relativo a las candidaturas, y por otro lado, el comportamiento mismo de los partidos o candidatos. Porque aunque los medios enfoquen a estos últimos, éstos no se mueven en un contexto vacío de instituciones. Partidos y candidatos se ven enfrentados no sólo entre ellos sino ante las oportunidades u obstáculos que el diseño institucional ofrece a su acción. En otras palabras, las instituciones cuentan. Este es un hecho que no debería pasar desapercibido por los analistas. Partidos y candidatos se mueven en un escenario institucional que no sólo le pone límite a sus aspiraciones sino que posibilita cierto tipo de acciones. Ahora bien, cuando hablo de instituciones, de diseño institucional, $i$ a qué me refiero?

En la tradición del pensamiento sociológico las instituciones son consideradas como pautas establecidas de comportamiento de individuos y/o grupos. Usualmente derivan de rutinas y hábitos. Se establecen socialmente como maneras de hacer las cosas y vuelven objetivo el orden social'. Desde este punto de vista, las instituciones no son las or-

1. Entiendo aquí por orden social, las configuraciones de conductas estables, regulares y predecibles. Ver Jon Elster, "El cemento de la sociedad". Barcelona: Gedisa, 1992. Hablar de objetividad del orden quiere decir considerar a este como dado a los individuos y grupos, les antecede y se les aparece como independiente de su quehacer pese a que es producto de ese su continuo quehacer. 
ganizaciones aunque es posible que éstas materializen roles institucionales. En otras palabras, las instituciones viven a través de las organizaciones pero las desbordan. Su existencia va más allá de cualquier organización en concreto. Organizaciones van y organizaciones vienen pero las instituciones se mantienen, persisten socialmente. De hecho, es por esta razón que el cambio social no puede darse por ruptura total entre dos formas de organizar la vida social. Como no es mi interés en este momento hablar sobre el cambio social y del rol que tienen en ese cometido las instituciones dejo aquí esta discusión. Por el momento quiero rescatar nada más la diferencia entre instituciones y organizaciones.

Por otra parte, las instituciones pueden ser formales e informales. Cuando hay una ley o reglamento de por medio que regula las pautas de comportamiento estamos frente a una institución formal. Sin esa ley o reglamento, las pautas de comportamiento pueden existir con igual o incluso con mayor fuerza. Entonces hablamos de instituciones informales. Se reconoce su existencia social de hecho aunque no por derecho. El quehacer de individuos y grupos fluye también por canales informales que de todas formas lo vuelven predecible. En otras palabras, no todo el comportamiento social está reglamentado jurídicamente aunque sí lo está sancionado (de manera positiva o negativa) socialmente. Instituciones formales e informales están allí para canalizar el comportamiento de los individuos y grupos. Cuando éstos recurren con mayor frecuencia y se someten a las instituciones formales como canales de acción nos acercamos a una situación de estado de derecho. Pero esta situación no tiene por qué darse. Cuando los individuos y grupos recurren con mayor frecuencia a las instituciones informales como canales de acción nos acercamos a una situación de debilidad del marco legal. Por supuesto que podemos estar en situaciones intermedias donde se combina el recurso a ambos tipos de instituciones.

Cuál ha sido el objetivo de traer toda esta discusión sobre las instituciones cuando este comentario lo hago a propósito de las coaliciones, divisiones, candidaturas independientes y tránsfugas políticos? Pues bien, todas estas son maneras de participar en el juego político partidista y electoral. Y como maneras de participar pueden ser consideradas como instituciones políticas. En la medida en que estén reguladas legalmente (por ejemplo en la Constitución de la República o en el Cógido Electoral) constituyen un diseño institucional formal. Caso contrario estamos ante instituciones informales ${ }^{2}$. Esto quiere decir que mi comentario no busca juzgar a determinados individuos o grupos sino más bien explorar las relaciones entre éstos y el diseño institucional formal. Es este tipo de examen el que me interesa por lo que de luz puede arrojar sobre la fortaleza y/o debilidad de nuestro diseño o marco institucional. ¿Y ello por qué? Porque en parte de ello depende la deseada, buscada pero todavía no realizada consolidación de instituciones democráticas en nuestro país.

\section{Sobre las coaliciones}

Puede parecer curioso, e incluso extraño para algunos, el siguiente planteamiento: en materia de coaliciones electorales, el sistema electoral salvadoreño diseñado para la disputa por los concejos municipales impone una lógica de comportamiento que se opone a la actual lógica con la cual los partidos diseñan su estrategia electoral. Dicho de otra manera: en la disputa por los concejos municipales los partidos políticos salvadoreños siguen una estrategia más apropiada para otro diseño institucional. Voy a desarrollar por partes esta idea.

En primer lugar, al hablar del sistema electoral no debemos olvidar que éste se compone de varios elementos que afectan la distribución de puestos de poder político a partir del caudal de votos que obtienen los diferentes partidos. El elemento que me interesa aquí refiere al criterio o principio de representación. Así tenemos sistemas electorales o bien mayoritarios o bien proporcionales. Para el caso de los concejos municipales, el código electoral vigente establece una representación mayoritaria. Es decir, la asignación de los escaños municipales recae sobre el partido o coalición que obtiene más votos. Según el código electoral basta la mayoría simple para que un partido o coalición se lleve todos los escaños del concejo municipal. Si un voto es la diferencia entre el primero y el se-

2. Eventualmente cualquiera de ellas podría llegar a ser parte del diseño institucional formal. Por ejemplo si jurídicamente se regula la existencia de las candidaturas independientes. 
gundo partido o coalición eso no interesa. Así por ejemplo, los 18 concejales (incluyendo al alcalde) que se disputan en San Salvador serán adjudicados al partido o coalición con más votos. No importa si la diferencia es de apenas un voto. Bajo esta lógica de competición la estrategia adecuada es sumar votos. Cuantos más votos mejor. Aquí hay una fuente institucional para impulsar la búsqueda de alianzas o coaliciones preelectorales.

Ahora bien, los partidos pueden planificar su estrategia electoral bajo otra lógica. Confiando en su propio caudal de votos pueden optar por competir por ellos mismos, sin necesidad de alianzas o coaliciones. El costo de éstas supone un reparto de cuotas de poder que probablemente no se desea. Sin embargo, si para las elecciones de marzo del 2000 no sólo partidos de la izquierda salvadoreña han buscado formar coaliciones (de las cuales se han concretado algunas) sino también del lado de la derecha se llegó a pensar en esa posibilidad, lo que se pone en evidencia (aunque tal vez no se le quiera reconocer) es la fuerza de la lógica de competición del diseño institucional. Hace ya medio siglo que el francés Maurice Duverger, al escribir su obra clásica «Los partidos políticos» planteó esta situación en los siguientes términos: el sistema electoral de mayoría simple produce bipartidismo. Por esta formulación, en ciencia política ha habido un largo debate sobre los términos empleados, si se trata de una ley o no, y sobre su validez o no. No me voy a meter en ese debate en este comentario pero no puedo dejar de tenerlo en cuenta a la hora de analizar e interpretar la información que la radio, televisión y prensa han ofrecido a la consideración del público. La lógica de sumar votos para ganar aunque sea por un voto al adversario empuja, quiérase o no, a la formación de bloques o coaliciones para ser alternativa real de poder. Si a esto agregamos el peso nacional que puede tener, por ejemplo, la alcaldía de San Salvador (en tanto plataforma para posibles candidaturas a la Presidencia), no resulta raro que sea allí donde con más fuerza opere el diseño institucional y uobligue» a partidos y candidatos a tenerle en cuenta. Aquí hay una razón institucional clara que puede impulsar a la búsqueda de coaliciones. Pero como se trata de una «ley» que no pasa por código alguno sino que se trata de una regularidad informal pue-

de ser «violada». $i$ Tiene consecuencias esta violación? ¿Reciben alguna sanción los partidos si actuan bajo otra lógica de competencia? Esto es algo que únicamente se puede responder a posteriori, es decir, hasta cuando se conocen los resultados electorales. Pero entonces para algunos partidos puede resultar demasiado tarde para cambiar de estrategia.

Lo dicho en los párrafos anteriores puede resumirse así: el diseño institucional para las elecciones de concejos municipales es un incentivo institucional para la búsqueda de coaliciones. Mientras permanezca vigente dicho diseño, y estemos ante la existencia de un multipartidismo, elección tras elección veremos los intentos exitosos o frustrados de formar coaliciones porque la representación por mayoría simple empuja inevitablemente hacia el bipartidismo.

Un segundo punto que quiero desarrollar en este comentario sobre las coaliciones tiene que ver con la estrategia real que siguen los partidos. Una cosa es la lógica de competencia que impone el diseño institucional y otra diferente es la lógica con la cual compiten los partidos. Como lo señalé antes estas dos lógicas no tienen por qué coincidir. Los partidos pueden rechazar la formación de coaliciones. Entonces vale la pena preguntarse si hay algún tipo de incentivos para que los partidos (o mejor dicho para que las cúpulas partidistas) no busquen la formación de bloques o coaliciones. En este sentido podría señalar la existencia de intereses particulares en las dirigencias partidistas o como diría la vox populi, el afán de poder es tal que impide a los partidos ver más allá de sus propios intereses partidistas 0 incluso de intereses 
personalistas. Sin embargo, para seguir en la línea del análisis de las fortalezas y debilidades de los diseños institucionales prefiero preguntarme por la existencia de incentivos institucionales. $Y$ he aquí que sí que los hay si tomamos en cuenta que las elecciones de concejos municipales se realizan de manera simultanea con las elecciones de diputados para la asamblea legislativa. Pero estas últimas se realizan bajo otra lógica institucional de competencia.

La disputa de los escaños legislativos se rige por el criterio de representación proporcional. Los escaños se reparten entre los partidos según los votos que éstos obtienen en cada circunscripción electoral. En el reparto de escaños pueden participar otros partidos diferentes del partido que obtiene más votos. En términos de teoría de juegos podría decirse que en la representación proporcional todos los jugadores ganan o por lo menos hay menos perdedores. Por el contrario, la representación mayoritaria es un juego de tipo suma-cero donde uno sólo es el que gana y todos los demás pierden. Esto quiere decir que la estrategia adecuada para las elecciones legislativas apunta a la participación por separado y cuantos más escaños están en disputa en la circunscripción más probabilidades de adjudicarse alguno tienen los partidos. Esto es válido también para los partidos pequeños ${ }^{3}$. Por tanto, la ilusión de obtener escaños legislativos actúa como incentivo para la participación por separado y el rechazo de coaliciones.

Lo planteado en el párrafo anterior también ya había sido sugerido hace cincuenta años por Duverger al estudiar las relaciones entre sistemas de representación proporcional y multipartidismos. $Y$ al igual que sobre la relación entre sistemas de representación por mayoría simple y bipartidismos, sobre estas otras relaciones también ha corrido mucha tinta desde entonces. Aquí nada más me interesa recordar la relación entre proporcionalidad y multipartidismo para caer en la cuenta de la fortaleza del diseño institucional. Termina imponiendo su lógica a los partidos en cuanto a la estrategia de coaligarse o no.
Uno puede imaginarse que los partidos pequeños deberían coaligarse para ganar más votos y tener mayores probabilidades de alcanzar escaños legislativos. Sin embargo, aunque la representación proporcional ya supone un incentivo para la participación por separado para todos los partidos, el diseño del sistema electoral proporcional en concreto puede ofrecer otros incentivos selectivos para ganar escaños por separado a los partidos pequeños. Por un lado, si el reparto de escaños es tal que ningún partido político cuente con la mayoría necesaria para la aprobación de determinadas leyes, los partidos pequeños adquieren un potencial de chantaje que los vuelve partidos relevantes por los escaños que pueden obtener al participar separadamente pues pueden convertirse en "fieles de la balanza". Pueden negociar a su favor con los partidos grandes porque éstos les necesitan en las discusiones de las plenarias y comisiones legislativas. Establecen un juego de toma y daca en el cual a cambio del apoyo de su fracción legislativa puede obtener un beneficio propio o para sus representados (si los tiene).

Por otro lado, la fórmula electoral concreta con que se reparten los escaños puede ser tal que los partidos pequeños son beneficiados directamente. Este es el caso de la fórmula Hare-resto mayor utilizada en El Salvador ${ }^{4}$. Hay otras fórmulas que favorecen a los partidos grandes como por ejemplo la fórmula D'Hondt utilizada en Argentina, Bolivia, Paraguay y República Dominicana.

Por tanto, más allá de las ambiciones personales de poder (inevitables en la lucha política) el diseño institucional establecido en el sistema electoral salvadoreño ofrece e impone su lógica a los partidos. Éstos bien podrían actuar bajo otra lógica pero en la práctica no ocurre así. Se pliegan al impulso institucional para la competencia por separado en elecciones parlamentarias. Si comparamos esta situación con lo que ocurre en las elecciones de concejos municipales vemos que, en este último caso, la lógica institucional no logra imponerse a los partidos puesto que allí el impulso va en dirección a la formación de coaliciones.

3. Los veinte escaños que se disputan en la circunscripción nacional favorecen la participación separada de los partidos pequeños. Sin embargo, los veinticuatro escaños legislativos que se disputan en ocho circunscripciones departamentales favorecen a los partidos más grandes como he tenido la oportunidad de mostrar en otros trabajos. Véase por ejemplo, «Los efectos de los sistemas electores», en Realidad, 58, San Salvador, Universidad Centroamericana José Simeón Cañas, 1997.

4. Fuera del ambiente académico esta fórmula es conocida como reparto de escaños por cociente electoral simple y según los residuos mayores. 
Pero no se trata de una debilidad institucional porque como ya lo señalé en otro párrafo elección tras elección vuelve a aparecer la tentación por las coaliciones. Se trata más bien de la necedad calculada de los partidos que creen poder adjudicarse el concejo municipal sin la necesidad de formar una coalición electoral. Pero como la lógica institucional para las elecciones municipales es de suma-cero, un partido es el que gana y los demás pierden. En estas condiciones, una coalición podría suponer una mejor estrategia para los potenciales perdedores porque de ganar, ganarían todos los miembros de la coalición y, supuestamente, los representados por dicha coalición. Para esta estrategia se contaria con la lógica del diseño institucional a su favor. Sin embargo, los estrategas partidistas son quienes finalmente calculan y deciden. El premio o el castigo a sus cálculos y decisiones vendrá dado por el conteo de los votos. Entonces será la hora de la verdad.

Hasta ahora he considerado por separado las lógicas institucionales de competencia que se derivan de los dos principios de representación utilizados para elegir diputados y concejos municipales. Sin embargo, el Código Electoral vigente establece la simultaneidad temporal de los dos tipos de elecciones. Digo simultaneidad temporal porque elegimos diputados y concejos municipales el mismo día y a la misma hora. No obstante utilizamos dos papeletas de votación diferentes. Esto supone la posibilidad de votar por un partido para la elección de diputados y por otro para la elección de concejos municipales. La pregunta lógica es: ¿hace uso el elector de esta posibilidad? Cualquiera sea la respuesta a esta cuestión es un elemento de juicio que los partidos pueden considerar a la hora de decidir si participan en coalición o separadamente en una de las elecciones o en ambas. Podemos suponer que si los estrategas partidistas consideran que el elector no hace uso de la posibilidad de votar por partidos diferentes, entonces conviene a los partidos la participación, o bien en coalición, o bien por separado, en ambas elecciones. Si los estrategas partidistas consideran que el elector marcaría la misma bandera o emblema partidista en las dos papeletas, entonces es lógico pensar que el diseño de la bandera o del emblema respectivo de una coalición sea un punto clave de negociación si se plantea que tal coalición sólo operaría en un tipo de elección y no en el otro. Este ha sido el caso de los debates en torno a una coalición de partidos que van del centro a la izquierda salvadoreña para la disputa del concejo municipal de San Salvador.

Es importante no subestimar lo planteado en el párrafo anterior como si sólo se tratara de un asunto de diseño de un emblema o bandera, como si sólo fuera un problema de colores, de estética. La clave en este asunto está en el llamado efecto arrastre de una votación a la otra. En este caso este efecto puede entenderse como el temor a que el voto por un concejo municipal termine arrastrando el voto por los diputados departamentales bajo la premisa de que el elector votará al mismo partido en las dos elecciones. Se trata de una situación que los estrategas partidistas pueden calcular y recomendar mirando los intereses partidistas primero. Como las elecciones de diputados crean la ilusión de asignarse escaños al participar separadamente, puede evaluarse como no conveniente una coalición en el nivel municipal para evitar un error del elector a la hora de marcar las papeletas. En la línea de lo que he venido desarrollando a lo largo de este comentario puedo decir que en el diseño institucional que supone la simultaneidad de las elecciones de diputados y concejos municipales hay otro incentivo institucional para la participación por separado, para la primacía de los intereses partidistas por sobre cualquier otro tipo de interés.

He planteado el efecto arrastre desde el voto municipal al voto departamental. Pero, ¿no podría pensarse que las cosas suceden a la inversa? Es decir, ¿no sería más bien que el voto departamental arrastrara al voto municipal? ${ }^{5}$ No parece que los estrategas partidistas piensen así a juzgar por el diseño de su campaña y propaganda política centrada más bien en las figuras de los alcaldes. Esto en el caso del municipio de San Salvador es harto claro. La proyección que tiene la alcaldía de San Salvador hacia el resto de la república, en términos de imagen, es clave para la disputa presidencial. Así quedó demostrado en los años sesenta cuando el democristiano Napoleón Duarte fue alcalde de San Salvador por dos periodos y posteriormente lanzó su candidatura para la presidencia en 1972.

5. Al referirme al voto departamental quiero decir el voto por diputados que compiten en el nivel departamental. Así mismo el voto municipal se refiere al voto en la disputa por los concejos municipales. 
Así también ocurrió con el arenero Armando Calderón Sol, también alcalde de San Salvador y luego presidente de la república. ¿Por qué no seguiría esta misma lógica el actual alcalde de San Salvador al buscar su reelección?

Otro argumento a favor del arrastre del voto desde el municipio al departamento está en la persistente manera de referirse a las elecciones municipales. Como en una especie de presidencialismito se habla más de elección de alcaldes antes que de elección de concejos municipales. Se resalta la figura de los candidatos a alcaldes antes que la composición de la lista de candidatos a concejales. Con la figura del candidato a gobemar la alcaldía se busca arrastrar el voto para todo el concejo municipal. En el caso de la disputa partidista entre ARENA y la coalición FMLN-USC en el municipio de San Salvador esto se traduce de la siguiente manera. Pareciera que importa más la figura de los candidatos Luis Cardenal y Héctor Silva que las respectivas propuestas de candidatos para los 17 concejales restantes. ¿O es que sólo de Luis Cardenal y Héctor Silva dependerá la marcha de la alcaldía de San Salvador? Esta importancia de las personalidades de los candidatos para alcaldes es comparable con la importancia que tiene la personalidad de cualquier candidato en las elecciones presidenciales. Por eso inicié este párrafo refiriéndome a la existencia de una lógica presidencial en chiquito, un presidencialismo en pequeño, en fin un presidencialismito.

Esta manera de considerar la lógica de la competencia por los concejos municipales a la hora de diseñar la estrategia partidista para la participación se convierte en pauta de comportamiento que en tanto regular, repetible, frecuente y estable (elección tras elección) bien puede considerarse, a la vez, como una institución informal. Es informal porque no deriva de una ley o reglamento alguno sino de la forma habitual que tienen los líderes y estrategas partidistas para enfrentar el desafío que supone una competencia electoral. Es una institución porque es anterior a los actuales líderes y estrategas partidistas, les orienta y establece cauces para su acción. Y como toda institución (en los términos planteados al inicio de este comentario) ésta es reacia a cambiar; con el agravante que ni siquiera existe un código legal que pueda modificarse para dar la impresión de un cambio institucional. En definitiva aquí vemos otra vez cómo las instituciones imponen su lógica a los ac- tores, en este caso, a los líderes y estrategas partidistas. Al imponérseles y arrastrarles bajo su lógica muestran su fortaleza. Y cuanto más coincidan, en sus efectos, la lógica del diseño institucional formal con la lógica de la institucionalidad informal, mayor poder coercitivo tiene la institucionalidad vigente.

\section{Sobre las divisiones}

En el apartado anterior me referí a la dinámica de la política de alianzas entre partidos desde una perspectiva institucionalista. Es decir, opté por una perspectiva que no es usual en el medio a la hora de comentar el acontecer político nacional. ¿Puede enfocarse de esta manera el fenómeno de las divisiones partidistas, ya sea en las bases de los partidos, o ya sea donde son más frecuentes, es decir, en sus cúpulas? ¿Significa que para nada intervienen los intereses particulares (personales) en las escisiones que registran los partidos salvadoreños tanto en momentos pre-electorales como en momentos post-electorales? Las divisiones, algunas de las cuales han llegado a los golpes entre militantes de un mismo partido, y que algunos medios televisivos han mostrado en imágenes ¿no son imputables a persona alguna?

Sin caer en la ingenuidad y sin considerar que nada tienen que ver intereses personalistas en la disputa por el poder, aquí como en cualquier parte del mundo, es importante no olvidar que la vida social transcurre por cauces institucionales que la vuelven predecible. Desde este punto de vista se puede prever qué puede ocurrir si se siguen o no los cauces institucionales. Se puede prever que una vez caldeados los ánimos en un mitin haya un desbordamiento de los canales institucionales establecidos, si los hay, para la disputa política intrapartidista. Pero vale la pena preguntarse, ise trata de una debilidad institucional o de un enfrentamiento entre instituciones formales e informales?

En algunas ocasiones las divisiones en los partidos pueden explicarse a partir de la existencia de facciones que luchan por el control del aparato partidista. El faccionalismo es un fenómeno hasta cierto punto normal en la vida de los partidos. Esto quiere decir que no es un fenómeno exclusivo de algunos de los partidos políticos salvadoreños. Puede encontrarse, por ejemplo, en el Partido Socialista Obrero Español (PSOE), en el Partido Popular Democrático (PPD) posteriormente Partido Socialdemócrata (PSD) de Portugal, en el Par- 
tido Socialista Chileno, en el Partido Revolucionario Democrático (PRD) de la República Dominicana, en el Partido Liberación Nacional (PLN) de Costa Rica, en el Partido Liberal (PL) de Honduras y en los emergentes partidos políticos de países de la ex europa del este. Por tanto, nada de extraño hay en la existencia de faccionalismo dentro del FMLN y de ARENA aunque éstos, como es de esperar, nieguen su existencia.

La disputa entre los dirigentes o barones de los partidos no tendría por qué desembocar en una división o escisión partidista. Que éste sea el resultado no depende sólo de aquella disputa sino del contexto institucional en el que ocurre. En este sentido vale la pena traer a cuenta lo ocurrido en 1985 en Honduras. Las elecciones presidenciales de ese año ofrecen una perspectiva para ver cómo las disputas en las cúpulas partidistas, y el personalismo a ellas asociado, no desembocan directamente en la escisión y, mucho menos, posterior creación de nuevos partidos. Honduras puede jactarse de poseer un milenario bipartidismo que se remonta hasta los grupos liberales y conservadores de la posindependencia. Pero en 1985 muy cerca estuvo de transformarse en multipartidismo. Las disputas y ambiciones de los principales líderes de los partidos Liberal y Nacional habían desembocado de hecho en siete candidaturas presidenciales: cuatro «liberales» y tres «nacionales». Sin embargo, gracias al recurso a la llamada ingeniería politica se evitó el fraccionamiento de ambos partidos. Para dichas elecciones se modificó la ley electoral de tal forma que los partidos podían presentar más de un candidato para la presidencia. De hecho, el candidato ganador (el liberal Azcona Hoyo) no fue el candidato más votado. La ley establecía que ganaría el partido con mayoría simple de votos $y$, dentro de las filas partidistas, ganaría el candidato con más votos' ${ }^{6}$. Pasadas esas elecciones y una vez enfriados los ánimos se retornó a la legislación anterior: un candidato por partido. La introducción de un diseño institucional (semejante a la histórica ley de lemas en el Uruguay $)^{7}$ pudo más que las disputas entre los líderes partidistas.
Al traer a cuenta el caso hondureño no pretendo sino ilustrar cómo interviene el contexto institucional en el que se mueven los partidos. En este caso para evitar la escisión partidista. Desde este punto de vista no importa tanto la existencia de disputas sino la forma cómo se resuelven o superan éstas. En este sentido, es posible señalar la existencia de diseños institucionales más o menos favorables para las crisis partidistas. Sin embargo, las disputas cupulares también pueden ser leídas como un choque entre dos tipos de institucionalidad: una democrática y otra autoritaria. Ambas implican formas específicas de comportamiento. Mientras una institucionalidad democrática (al interior de los partidos) exige el acatamiento a la regla de la mayoría y del debate intemo, la institucionalidad autoritaria implica arbitrariedad, ausencia de debate e imposición. Si en el ambiente extra partidista poco a poco se extienden principios democráticos tarde o temprano esos principios se cuelan al interior de los partidos. Pero, ¿están éstos listos para acogerlos en su interior? Al hacer esta reflexión hay que recordar que en El Salvador no tenemos experiencia democrática previa y que la usual manera de resolver las cosas ha obedecido a patrones autoritarios. Por tanto, lo que vemos al interior de los partidos, en términos de disputas cupulares por el control del aparato partidista y de los recursos que ello implica, es de la misma naturaleza de lo que vemos fuera de ellos. Es decir, una prolongada lucha entre dos formas de hacer política: una autoritaria (heredada del pasado y a la que estamos más acostumbrados) y otra democrática. Esta lucha entre dos lógicas institucionales está asociada con el cambio de régimen del que apenas hace cinco años hemos salido. La tragedia para el nuevo régimen está en los problemas que tiene para consolidarse. ¿Y puede haber democracia sin partidos democráticos? ¿Es posible la democracia si en los partidos políticos no rigen los principios democráticos? En síntesis, creo que los problemas del divisionismo partidista hay que leerlos en clave de los problemas que conlleva la consolidación demo-

6. El candidato del partido Nacional, pese a ser el candidato más votado perdió las elecciones pues su partido no logró la mayoría simple.

7. Los Blancos y los Colorados podían presentar más de un candidato en elecciones presidenciales. Ganaba el candidato con más volos dentro de la lista del partido mayoritario. 
crática. Los partidos deben crear y atenerse a unas reglas de juego que les permitan resolver sus problemas internos de manera pacífica y democrática.

\section{Sobre las candidaturas independientes y los tránsfugas políticos}

El 29 de octubre el Tribunal Supremo Electoral (TSE) frustró las aspiraciones de siete ciudadanos salvadoreños, que pretendían presentarse como candidatos a diputados en las elecciones de marzo del 2000 , al declarar sin lugar sus peticiones de inscripción como candidatos independientes del respaldo de partido político alguno. El argumento último del TSE se basa en el monopolio que tienen los partidos sobre la representación política según queda establecido en la Constitución Política. No me voy a meter al debate jurídico de este asunto pues para eso están allí los peritos en jurisprudencia. Me interesa más bien comentarlo desde la perspectiva de la ciencia política contemporánea. En este sentido, vale la pena traer a cuenta el principio de accountability que bien podríamos traducir como la rendición de cuentas. En las democracias representativas existen varios mecanismos para que los funcionarios públicos rindan cuentas de sus decisiones y actuaciones a la sociedad. En nuestro país ya se ha practicado este mecanismo institucional por medio de la interpelación. Sin embargo, las elecciones son también mecanismos institucionales para que los funcionarios públicos, que lo llegan a ser por vía electoral, se enfrenten al juicio de la ciudadanía. Desde este punto de vista, la reelección de un funcionario (presidente, diputado o concejal municipal) se considera como una evaluación positiva de su gestión, como un premio a su desempeño. Su no reelección significa una evaluación negativa de su gestión.

Cuando la representación política es monopolizada por los partidos políticos, son éstos los que finalmente son evaluados por la gestión realizada por los funcionarios públicos que recibieron el apoyo partidista. Desde este punto de vista, no sólo la reelección de un funcionario específico sino también el triunfo del mismo partido (aunque con diferente candidato) significa una evaluación positiva de parte del electorado. Como, por definición, los partidos buscan alcanzar o mantenerse en el poder implementarán políticas para ganar votos. Los partidos en el poder (presidencial, parlamentario o municipal) toman en cuenta que de su desempeño depende su futuro político. Un mal desempeño les puede costar una disminución de votos tal que pierdan el poder del que gozaban. De aquí que las elecciones sean también un mecanismo de rendición de cuentas de los partidos a la ciudadanía. Pero, ¿qué pasaría si no median los partidos entre la sociedad y el estado? Es decir, ¿cómo podría garantizarse la accountability si acceden al poder candidatos independientes?

Plantear las cosas en los términos de los párrafos anteriores no significa un apoyo a la actual gestión de los partidos políticos salvadoreños. Se entiende que haya un descontento total con los partidos por parte de los ciudadanos que han buscado su participación independiente en las próximas elecciones. Se entiende también que quieran ejercer un contrapeso a la representación partidista bajo el supuesto de que siendo independientes de vínculos partidistas gozan de mayor libertad a la hora de tomar decisiones. Se supone que no mirarán intereses partidistas sino intereses nacionales, o como mínimo departamentales puesto que como candidatos a diputados ese es el ámbito de su representación primera. Pero, ¿qué garantía tiene la ciudadanía de que las cosas serán así? ¿Cómo podría castigarse con el voto a un diputado independiente si ha tenido un mal desempeño? Incluso podría presentarse el caso de candidatos independientes que, a sabiendas de la imposibilidad del voto de castigo para su cargo aprovechasen para sí su período para el cual habría sido elegido.

Por otra parte, si se quiere avanzar en una «liberalización» de la representación política mediante las candidaturas independientes bien podria ir experimentándose en el nivel municipal. De hecho esto es lo que existe en Guatemala y Nicaragua. En ambos países se permiten candidaturas independientes, con respaldo de comités cívicos, para puestos de representación municipal no para diputados departamentales y mucho menos para diputados de ámbito nacional.

Desde una lógica institucional los cambios son graduales. No extraña pues la resistencia institucional al cambio desde los partidos y desde el TSE. No podía ser de otra manera. Por tanto, sin rechazar la idea de balancear la representación partidista habría más bien que pensar en otro tipo de controles en el ejercicio político por parte de la ciudadanía. Finalmente es esto lo que habría que buscar: una ciudadanía activa que hace valer sus derechos incluso frente a los que se supone son sus represen- 
tantes. Aquí pues lo que tenemos es un problema de evidente debilidad institucional, un problema que afecta a la esencia misma de la representación política democrática.

El otro fenómeno al que me referiré en este apartado es el del transfuguismo político porque al igual que las candidaturas independientes apunta a la debilidad del marco institucional. El tránsfuga político es aquel que siendo militante de un partido político específico decide en determinado momento pasarse a las filas de otro partido. En general, el tránsfuga puede pertenecer bien a la base partidista o bien a la cúpula. El fenómeno es el mismo. Por supuesto que adquiere más notoriedad cuando el tránsfuga pertenece a la cúpula y mucho más si aquél es un funcionario público, como por ejemplo un alcalde. A la fecha de escribir este comentario son más de diez los alcaldes que «han cambiado de camiseta" independientemente del partido. Los casos más notorios, por obra y gracia de algunos medios de prensa escrita, se han dado en las filas de los partidos ARENA y FMLN. Como la fuga desde un partido a otro se da en el momento pre-electoral se interpreta como un resultado de las ansias de poder de aquellos que quieren ser elegidos para un segundo periodo a cuya candidatura se opone la cúpula partidista. Ante este bloqueo el tránsfuga busca acogida en otro partido ideológicamente cercano como en los casos de los alcaldes areneros que se han pasado a las filas del PCN. El partido que recibe al tránsfuga lo hace bien porque reconoce su labor como funcionario político o bien porque pretende captar los votos de los seguidores del tránsfuga para fortalecerse electoralmente. Sin embargo, como la fuga obedece en este caso a una negativa en el partido de origen a la re-elección del alcalde (lo cual supone una evaluación negativa a su gestión), la acogida en el partido de llegada pareciera obedecer más bien a la segunda lógica: la captación de votos.

En términos institucionales, el transfuguismo apunta a la debilidad de la organización partidista para resolver las diferencias en su seno. Sin embargo, también puede hacerse otra lectura. El transfuguismo manifiesta la debilidad de los lazos entre militantes y la estructura partidista. Transparenta la debilidad de sus lealtades mutuas. Es en otras palabras, señal de erosión de identidades partidistas. Si se está contra las candidaturas independientes porque éstas podrían atentar contra la fortaleza de los partidos (aunque esto no se diga a voces) también debería estarse en contra de los tránsfugas por la misma razón. Al final de cuentas el tránsfuga político es alguien que se independiza (se vuelve independiente) de los lazos que le unían a su anterior partido ${ }^{8}$. Pero si se rechazan las unas y se aceptan los otros es que algo anda mal en la legislación electoral. Más aún si se considera que ambos fenómenos pueden llegar a convertirse, en determinadas condiciones, en atentados contra la fortaleza de cualquier institucionalidad democrático que se jacte de ser representativa. Al menos desde el punto de vista de la rendición de cuentas ante la ciudadanía.

\section{Álvaro Artiga González}

8. Aunque aquí me he detenido a comentar el caso de los alcaldes tránsfugas, no hay que olvidar que el mismo fenómeno se da también entre los diputados de la asamblea legislativa. Allí también aparecen los diputados independientes (tránsfugas). ¿Qué dice la ley en este caso? ¿Qué diferencia habría entre un diputado que se independiza del partido que lo postuló y un diputado que se postula de manera independiente antes de las elecciones? 